\title{
Wind tunnel experiments of tracer dispersion downwind from a small scale physical model of a landfill
}

\author{
Matteo Carpentieri, Andrea Corti, Luca Zipoli \\ Environmental Modelling and Software 19(10), 881-885 [2004] \\ doi: $10.1016 /$ j.envsoft.2004.03.002
}

\begin{abstract}
Wind tunnel experiments have been carried out on a small-scale physical model of a municipal waste landfill (MWL) in the CRIACIV (Research Centre of Building Aerodynamics and Wind Engineering) "environmental" wind tunnel in Prato (Italy). The MWL model simulates a landfill whose surface is higher than the surrounding surface, applying a 1:200 scaling factor. Modelling an area source such as landfill is a difficult task for numerical models due to turbulence phenomena that modifies the flow near the source increasing ground level concentration (GLC). For the specific task a new set-up of the wind tunnel has been developed, with respect to previous studies carried out on line and point sources physical models. The tracer used in the experiments was ethylene, suitable for non-buoyant plume conditions, typical for MWL emissions. A detailed result data base has been obtained in terms of GLC and concentration profiles as well as flow turbulence and velocity field characterisation.
\end{abstract}

Keywords: Wind tunnel, concentration profiles, landfill, physical modelling, experimental data.

\section{INTRODUCTION}

Both numerical and physical models can be valid instruments for assessing pollutants dispersion in the atmosphere. Models have many advantages with respect to full-scale measurements and can be used to support monitoring networks in the evaluation of pollution levels, as established by the European legislation (96/92/EC).

A large amount of commercial and research numerical models are currently available for a wide range of different applications, depending on the specific case study characteristics (terrain configuration, meteorological data, source and pollutant typology). Evaluation of numerical code result accuracy and definition of the optimal set up are very important tasks.

Small-scale physical models are very useful for developing, improving or testing numerical codes, which mainly rely on empirical parameters and on field data sets affected by large uncertainties (Schatzmann et al., 1997). 
In this application the dispersion of a tracer from a municipal waste landfill (MWL) was modelled, in order to evaluate the diffusional path of emitted pollutants (mainly odours and hydrocarbons). Pollutant dispersion from MWL is strongly influenced by fully turbulent, localised flows around the plant (specifically referring to a relief one). These conditions represent a challenging problem for numerical models in order to have a sufficient accuracy of the results.

Starting from these considerations the aim of this study was to build an experimental data set, useful for characterising dispersion phenomena with the aim of numerical codes calibration.

\section{EXPERIMENTAL SET-UP}

The experiments were undertaken in the environmental boundary layer wind tunnel (BLWT) of CRIACIV, located in Prato, Italy. This BLWT is a suck-down open channel wind tunnel placed inside a closed shed of the Florence University Institute. The working section size is $2.4 \mathrm{~m} \mathrm{x} 1.6 \mathrm{~m}$ x $4 \mathrm{~m}$, in terms respectively of width, height and length. The wind tunnel has not any devices for temperature stratification simulation, thus only neutral atmosphere can be represented.

Wind flow measurements in the wind tunnel were performed by means of Pitot tubes and single hot wire anemometers. Velocity and turbulence characteristics were investigated in details as useful parameters to assess the correct reproduction of the full-scale boundary layer (BL).

Tracer concentration measurement system, with a powered configuration with respect to previous applications (see, e.g., Contini, 1998; Corti et al., 2000; Manfrida et al. 2001), is based on two parallel Flame Ionisation Detectors (FID) devices, and allows up to 24 sample points located inside the working section of the wind tunnel.

The small-scale model (scaling factor 1:200) simulates an operating landfill in relief. The full-scale height is $15 \mathrm{~m}$ and the base width is about $200 \mathrm{~m}$. The model (see figure 1) is truncated-pyramidshaped with a square base and a top area size $476 \times 476 \mathrm{~mm}^{2}$ at a height of $75 \mathrm{~mm}$.

An artificial boundary layer, $0.7 \mathrm{~m}$ depth $\left(\mathrm{H}_{\mathrm{ref}}\right)$ corresponding to $140 \mathrm{~m}$ at full scale, was developed using spires vortex generator (Irwin, 1981) and roughness distribution. 
An accurate evaluation of the flow in the wind tunnel, performing different set-ups, was carried out in a previous study (Zipoli, 2002). Vertical and longitudinal velocity profiles showed, at distance $\mathrm{x} / \mathrm{H}_{\text {ref }}=0.81$ ( $\mathrm{x}$ axis representing the flow direction with the origin in the centre of the landfill), the effect of the landfill shape on the flow, with an increase of the turbulence and a decrease of the wind velocity near the ground. This effect is no more present at a distance $\mathrm{x} / \mathrm{H}_{\mathrm{ref}}=2.24$.

In this study a new set up was applied, varying the roughness parameter in the test section, in order to assess the influence of this parameter with respect to the previous experiments. A well-developed and stable turbulent flow was performed, having a sufficient reproduction of the flow and having negligible variation in the longitudinal direction. The measured profiles (figure $2-$ the values are normalised with $U_{\text {ref, }}$ i.e. the wind speed measured out of the BL, at a reference height of $1.4 \mathrm{~m}-$ and figure 3) show a good agreement with the power law of the wind profile (the calculated exponent varying with the distance around a mean value of 0.155 ) as well as the logarithmic law, with the assumption of $\mathrm{u}^{*} / \mathrm{U}_{\text {ref }}$ equal to $0.050\left(\mathrm{u}^{*}\right.$ being the friction velocity) and the roughness length $\mathrm{z}_{0}$ equal to $0.25 \mathrm{~mm}$ (equal to $0.05 \mathrm{~m}$ at full scale), that is to say $\mathrm{z}_{0} / \mathrm{H}_{\text {ref }}=3.57 \cdot 10^{-4}$.

The biogas composition $\left(\mathrm{CO}_{2}, 45 \%, \mathrm{CH}_{4}, 55 \%\right)$ was estimated using the LandGEM (Landfill Gas Emission Model) code, developed by US EPA Control Technology Center. Assuming 80\% biogas capture efficiency, a biogas flow rate of $38.1 \mathrm{~g} \mathrm{~s}^{-1}$ was calculated. Usually biogas emitted from a landfill has quite the same temperature as atmosphere and density is similar too, so that no plume rise effects were accounted for. Thus, emission scaling was performed using a standard equation for neutrally buoyant releases (Robins, 1977):

$$
\frac{\mathrm{CU}_{\mathrm{ref}} H_{\mathrm{ref}}^{2}}{Q}=f\left(\frac{W_{\mathrm{em}}}{U_{\mathrm{ref}}}\right)
$$

where Q represents volumetric flow rate, $\mathrm{H}_{\text {ref }}$ is a reference normalisation length (in this case $\mathrm{H}_{\text {ref }}$ is the boundary layer depth), $\mathrm{C}$ is the volumetric concentration and $\mathrm{W}_{\mathrm{em}}$ is the vertical emission velocity. 
The wind speed at a reference height of $10 \mathrm{~m}$ was set to $2 \mathrm{~m} \mathrm{~s}^{-1}$, both at full scale and at reduced scale. This means that $\mathrm{W}_{\mathrm{em}}$ must be the same at reduced scale and at full scale. This was not possible to obtain due to the scarce tracer flow at the source. For this reason the flow rate was arbitrarily increased setting no limitation for the reduced scale wind velocity. However this approximation is still valid if the tracer flow speed is negligible with respect to the wind flow (Obasaju and Robins, 1998).

The main characteristics of the scaled model related to full scale properties are reported in table 1. In order to analyse the spatial distribution of the tracer downwind of the source, several concentration profiles were carried out: transverse profile measurements at height $\mathrm{z} / \mathrm{H}_{\mathrm{ref}}=0.014$ (equivalent to $2 \mathrm{~m}$ at full scale) at different distances $\mathrm{x} / \mathrm{H}_{\text {ref }}$ downwind of the landfill $(0.86,1.71$, 2.24, 2.57, 2.74 and 3.24); transverse profile measurements at height $\mathrm{z} / \mathrm{H}_{\text {ref }}=0.107$ (source height) at different distances $\mathrm{x} / \mathrm{H}_{\text {ref }}$ downwind of the landfill $(0.86,1.71,2.57$ and 3.24); vertical profile measurements at different distances $\mathrm{x} / \mathrm{H}_{\text {ref }}$ downwind of the landfill $(0.86,1.71,2.57$ and 3.24).

For each measurement set, a standard closed circuit wind tunnel analytical procedure was applied, evaluating the background level concentration upwind the source twice, at the beginning and at the end of the measurement set, supposing a linear background concentration growing trend (Contini, 1998). Concentration measurements were carried out with an averaging time of the FID signal of about $270 \mathrm{~s}$ and a sampling frequency of $500 \mathrm{~Hz}$.

Due to the large amount of variables affected by random error and the non-linear interaction between them, an evaluation of the global accuracy of a single concentration measurement is very difficult to be carried out. Thus several repeatability tests of the results were performed in order to assess the data accuracy and to monitor the measurement chain performance.

\section{RESULTS}

Transverse mean concentration profiles, measured at $\mathrm{z} / \mathrm{H}_{\text {ref }}$ height of 0.014 (corresponding to $2 \mathrm{~m}$ at full scale) are reported in figure 4. A rapidly decrease before a stabilisation at a non-dimensional distance $\mathrm{x} / \mathrm{H}_{\text {ref }}=2.24$ can be observed, as effect of both source emission and flow instability 
downwind of the source. The distribution of the mean concentration at height $\mathrm{z} / \mathrm{H}_{\mathrm{ref}}=0.014$ is reported in figure 5, obtained as interpolation of the measurement field results. Transverse mean concentration profiles were also measured at the source height $\left(\mathrm{z} / \mathrm{H}_{\mathrm{ref}}=0.107\right)$, as reported in figure 6. Comparing these results with concentration measured at $\mathrm{z} / \mathrm{H}_{\text {ref }}=0.014$ (figure 4), a remarkable increased uniformity of data can be noticed. Vertical mean concentration profiles were also measured, as reported in figure 7. From reported data is possible to foreground that the pollutant remains mainly near the ground, with a low vertical dispersion.

In order to validate the obtained results measurement tests were duplicated both for transverse and vertical profiles at different distances from the source. Several tests were also performed in order to verify twin measurement by the two different FIDs. A good reproducibility was observed, with a relative error usually lower than $10 \%$. Highest errors were observed near the source, where the flow perturbation due to the landfill is higher, and in correspondence of the lower concentration points.

A detailed analysis of downwind diffusion was performed, basing on the mean height of the plume and both vertical and horizontal spread:

$$
\begin{aligned}
& \dot{i} z>=\frac{\int z C(z) d z}{\int C(z) d z} \\
& z-i z>i \\
& i \\
& \dot{\iota}_{2} C(z) d z \\
& \text { i } \\
& \text { i } \\
& \int i \\
& \text { i } \\
& \sigma_{Z}^{2}=i \\
& \text { i } \\
& \sigma_{Y}^{2}=\frac{\int y^{2} C(y) d y}{\int C(y) d y}
\end{aligned}
$$

In figure 8 the mean height versus the distance from the source is reported, while in figure 9 both vertical and horizontal spread variations with respect to the distance from the source are reported. 
A constant growth of the plume $(<\mathrm{Z}>)$ can be observed from results reported in figure 8 , with a stabilising trend when the distance increases. A key result obtained is that the mean height of the plume $(<\mathrm{z}>)$ for the nearest profiles is lower than the source height $\left(\mathrm{z} / \mathrm{H}_{\text {ref }}=0.107\right)$, similar to a "downwash effect" on the source.

\section{CONCLUSIONS}

A set of experiments concerning the dispersion of a non-buoyant tracer emitted from a landfill, using a small-scale physical model, was carried out in a boundary layer wind tunnel facility.

Results can be useful for characterisation of atmospheric dispersion in similar situations (at fullscale) and for validation and/or comparison of mathematical models.

Despite the difficulties of measuring low concentrations, and of modelling the complex flow near the landfill, the experiments showed good reproducibility, with relative variation less than $10 \%$, confirming the experimental set-up validity.

The results analysis allowed the evaluation of the dispersion parameters, which showed how the flow downwind of the landfill, due to induced turbulence, increases the ground level concentration (GLC) with a contemporaneous high variability of GLC near the source.

A phenomenon similar to the "downwash effect" was foregrounded too, with the analysis of the mean plume height $(<\mathrm{z}>)$, together with a high ground reflection effect due to both low emission height and the absence of buoyant phenomena.

Higher GLC data obtained in the model scale field appear to be largely influenced by these nearthe-source effects, being located immediately close to the landfill.

\section{ACKNOWLEDGEMENTS}

The authors would like to acknowledge the support given by SITA FD, particularly from Mr. Livio Puglierin, for providing emission data and plant characteristics.

\section{REFERENCES}

Contini, D., 1998. Studio di diffusione di inquinanti gassosi su modelli in scala ridotta in galleria del vento (Gaseous pollutants dispersion study with wind tunnel small scale models). PhD thesis, University of Florence. 
Corti, A., Contini, D., Manfrida, G., Procino, L., 2000. Environmental wind tunnel study on a municipal waste incinerator. Environmental Monitoring and Assessment 65 (1-2) 191-199.

Irwin, H. P. A. H., 1981. The design of spires for wind simulation. Journal of Wind Engineering and Industrial Aerodynamics 7 361-366.

Manfrida, G., Corti, A., Contini, D., 2001. Comparison between different dispersion models using wind tunnel smallscale measurements. International Journal of Environment and Pollution 16 216-226.

Obasaju, E.D., Robins, A.G., 1998. Simulation of pollution dispersion using small scale physical models - an assessment of scaling options. Environmental Monitoring and Assessment 52 239-254.

Robins, A.G., 1977. Wind tunnel modelling of plume dispersal. Central Electricity Generating Board, Research Division, Marchwood Engineering Laboratories, Report R/M/R247.

Schatzmann, M., Rafailidis, S., Pavageau, M., 1997. Some remarks on the validation of small-scale dispersion models with field and laboratory data. Journal of Wind Engineering and Industrial Aerodynamics 67\&68 885-893.

Zipoli, L., 2002. Misure anemometriche e diffusionali in galleria del vento applicate al caso di emissione di tracciante inquinante da discariche di R.S.U. (Anemometric and dispersion measurements in wind tunnel applied to a solid waste landfill tracer emission). Graduation thesis, University of Florence.

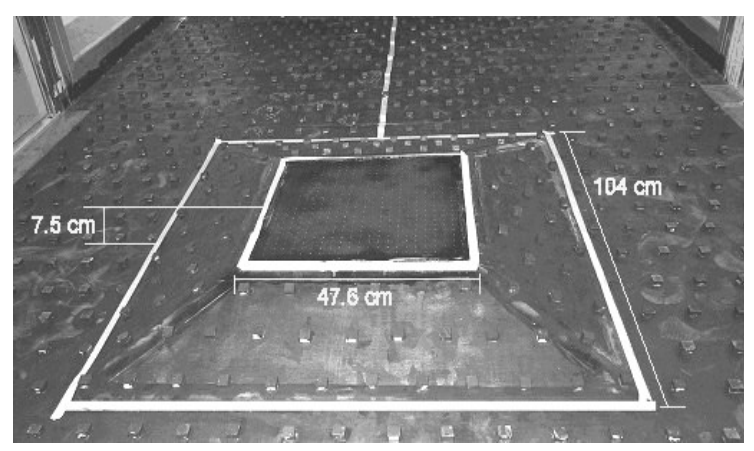

Figure 1 - Small-scale (1:200) model of the landfill

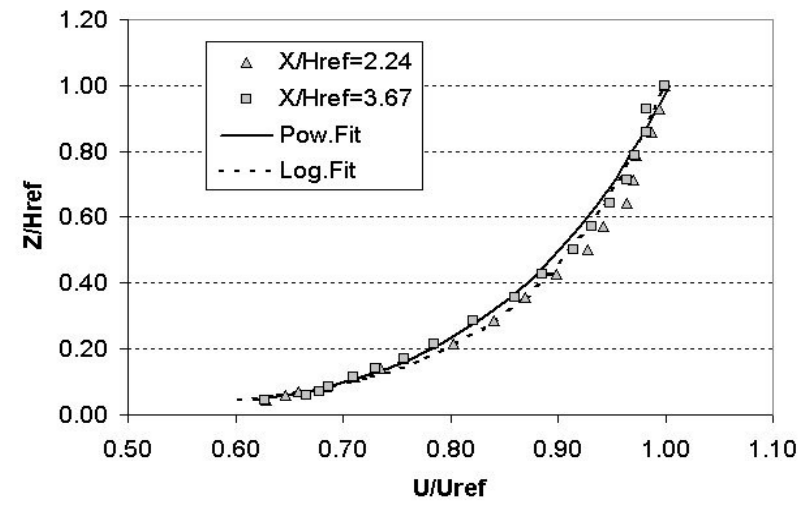

Figure 2 - Velocity profiles at different distances downwind the source

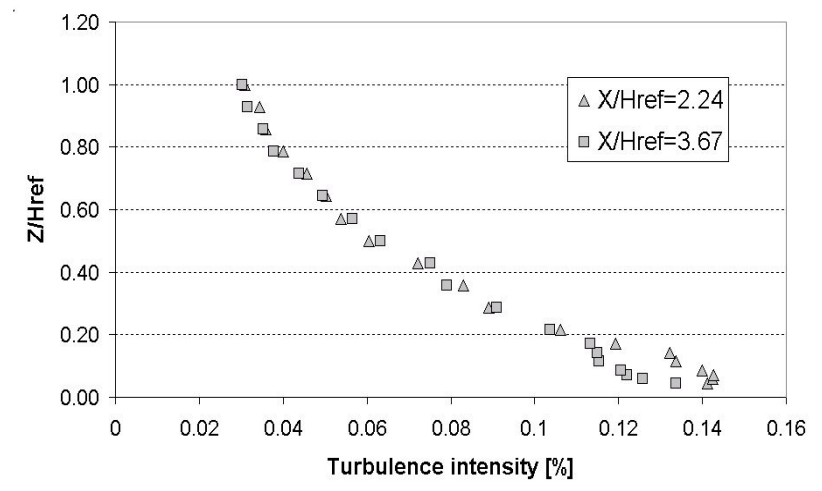

Figure 3 - Turbulence intensity at different distances downwind the source

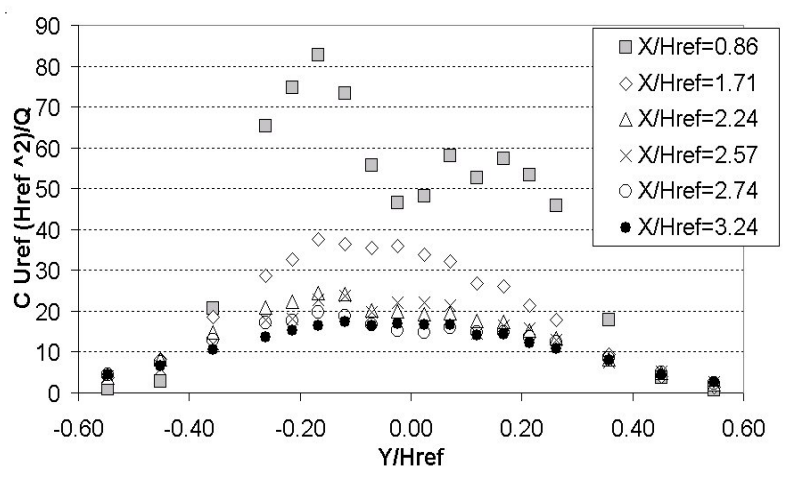

Figure 4 - Transverse non-dimensional mean concentration profiles at $\mathbf{z} / \mathbf{H}_{\text {ref }}=\mathbf{0 . 0 1 4}$. 


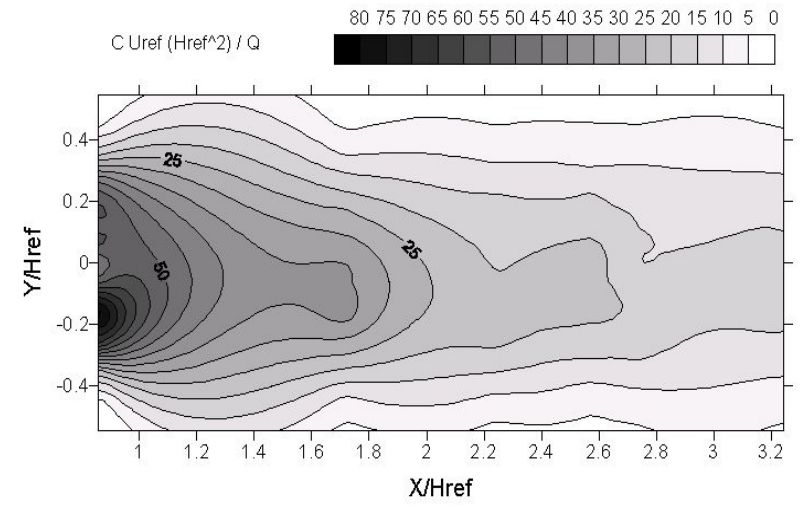

Figure 5 - Non-dimensional mean concentration map at $\mathbf{z} / \mathbf{H}_{\text {ref }}=\mathbf{0 . 0 1 4}$.

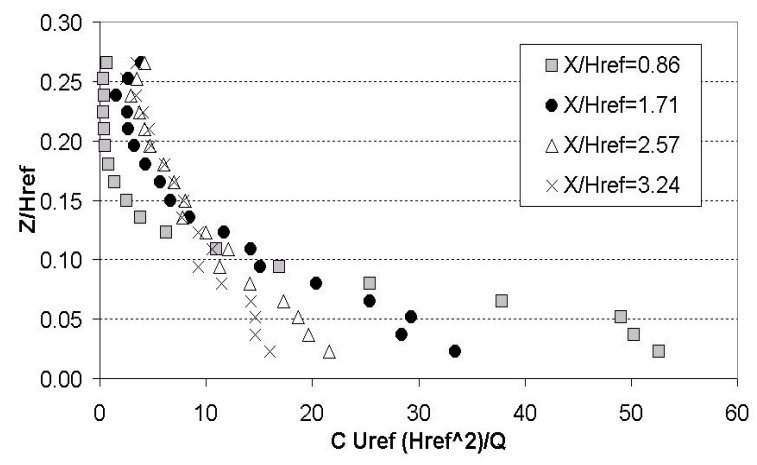

Figure 7 - Vertical non-dimensional mean concentration profiles.

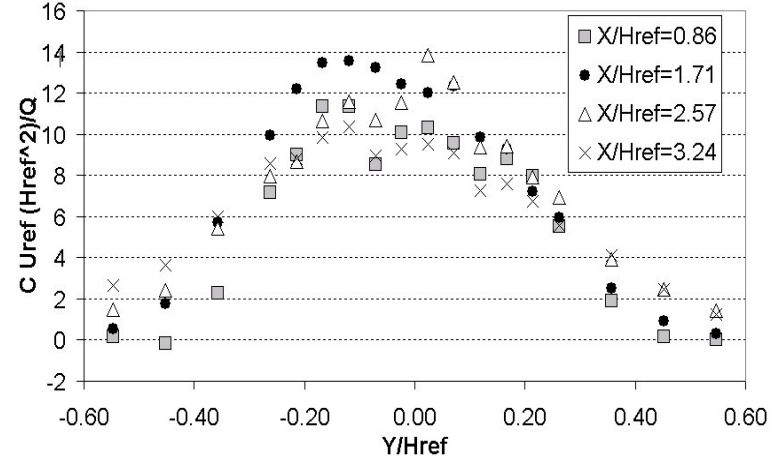

Figure 6 - Transverse non-dimensional mean concentration profiles at $\mathrm{z} / \mathbf{H}_{\text {ref }}=\mathbf{0 . 1 0 7}$.

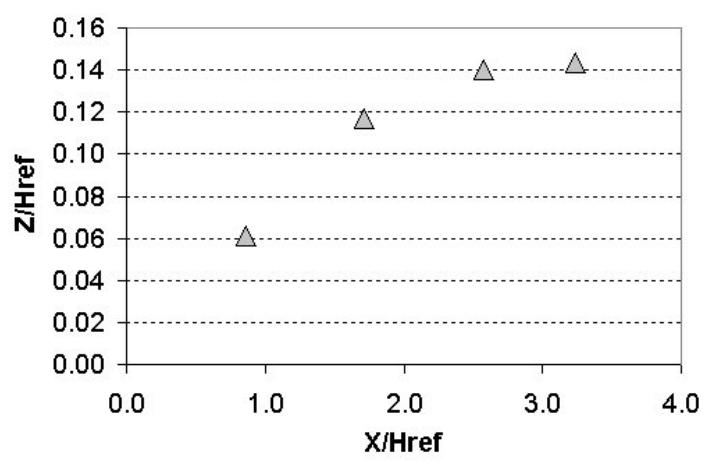

Figure 8 - Mean height of the particles versus distance from the source

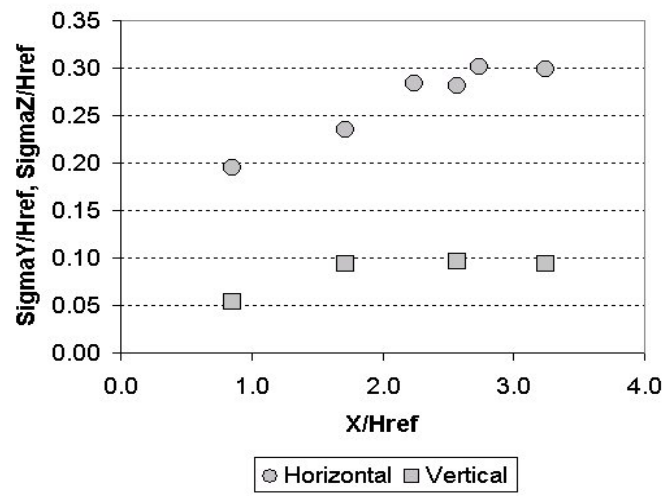

Figure 9 - Vertical and horizontal spread versus distance from the source.

\begin{tabular}{ccc}
\hline PARAMETER & FULL SCALE & REDUCED SCALE \\
\hline Source height & $15 \mathrm{~m}$ & $0.075 \mathrm{~m}$ \\
Emission area & $8100 \mathrm{~m}^{2}$ & $0.2025 \mathrm{~m}^{2}$ \\
Roughness length $\left(\mathrm{z}_{0}\right)$ & $0,05 \mathrm{~m}$ & $2.5 \cdot 10^{-4} \mathrm{~m}$ \\
Tracer flow rate $(\mathrm{Q})$ & $0.032 \mathrm{~m} \mathrm{~s}^{-1}$ & $8.0 \cdot 10^{-6} \mathrm{~m}^{3} \mathrm{~s}^{-1}$ \\
Vertical emission velocity $\left(\mathrm{W}_{\mathrm{em}}\right)$ & $3.9 \cdot 10^{-6} \mathrm{~m} \mathrm{~s}^{-1}$ & $3.9 \cdot 10^{-5} \mathrm{~m} \mathrm{~s}^{-1}$ \\
Wind profile exponent $\alpha_{\mathrm{p}}$ & 0.155 & 0.155 \\
Wind velocity at height $\mathrm{z} / \mathrm{H}_{\text {ref }}=0,07\left(\mathrm{U}_{10}\right)$ & --- & $2 \mathrm{~m} \mathrm{~s}^{-1}$ \\
Wind velocity at source height $\left(\mathrm{U}_{\mathrm{em}}\right)$ & --- & $2.13 \mathrm{~m} \mathrm{~s}^{-1}$
\end{tabular}


Roughness Reynolds number $\left(\mathrm{u}^{*} \mathrm{z}_{0} / \mathrm{v}\right)$

Density ratio $\left(\rho_{\text {gas }} / \rho_{\mathrm{a}}\right)$

$---$

2.3

Boundary layer depth $\left(\mathrm{H}_{\mathrm{ref}}\right)$

$140 \mathrm{~m}$

$0.7 \mathrm{~m}$

Table 1 - Main parameters used in the scaled model and full-scale values. 